\title{
Polyaniline Synthesized by Different Dopants for Fluorene Detection via Photoluminescence Spectroscopy
}

\author{
Mahnoush Beygisangchin ${ }^{1,2}$, Suraya Abdul Rashid $1, * \mathbb{C}$, Suhaidi Shafie $2,3, * \mathbb{D}$ and Amir Reza Sadrolhosseini ${ }^{4}$ \\ 1 Nanomaterials Processing and Technology Laboratory, Institute of Nanoscience and Nanotechnology, \\ University Putra Malaysia, Serdang 43400, Malaysia; m.beygi2300@yahoo.com \\ 2 Functional Nanotechnology Devices Laboratory, Institute of Nanoscience and Nanotechnology, \\ University Putra Malaysia, Serdang 43400, Malaysia \\ 3 Faculty of Engineering, University Putra Malaysia, Serdang 43400, Malaysia \\ 4 Magneto-Plasmonic Laboratory, Laser and Plasma Research Institute, Shahid Beheshti University, \\ Tehran 1983969411, Iran; amir17984818@gmail.com \\ * Correspondence: suraya_ar@upm.edu.my (S.A.R.); suhaidi@upm.edu.my (S.S.); \\ Tel.: +603-9769-7538 (S.A.R.); +603-9769-6307 (S.S.)
}

check for updates

Citation: Beygisangchin, M.; Abdul Rashid, S.; Shafie, S.; Sadrolhosseini, A.R. Polyaniline Synthesized by Different Dopants for Fluorene Detection via Photoluminescence Spectroscopy. Materials 2021, 14, 7382. https://doi.org/10.3390/ma14237382

Academic Editor: Mario Culebras Rubio

Received: 14 October 2021

Accepted: 26 November 2021

Published: 2 December 2021

Publisher's Note: MDPI stays neutral with regard to jurisdictional claims in published maps and institutional affiliations.

Copyright: (C) 2021 by the authors. Licensee MDPI, Basel, Switzerland. This article is an open access article distributed under the terms and conditions of the Creative Commons Attribution (CC BY) license (https:/ / creativecommons.org/licenses/by/ $4.0 /)$.
Abstract: The effects of different dopants on the synthesis, optical, electrical and thermal features of polyaniline were investigated. Polyaniline (PANI) doped with p-toluene sulfonic acid (PANI-PTSA), camphor sulphonic acid (PANI-CSA), acetic acid (PANI-acetic acid) and hydrochloric acid (PANI-HCl) was synthesized through the oxidative chemical polymerization of aniline under acidic conditions at ambient temperature. Fourier transform infrared light, X-ray diffraction, UV-visible spectroscopy, field emission scanning electron microscopy, photoluminescence spectroscopy and electrical analysis were used to define physical and structural features, bandgap values, electrical conductivity and type and degree of doping, respectively. Tauc calculation reveals the optical band gaps of PANIPTSA, PANI-CSA, PANI-acetic acid and PANI-HCl at 3.1, 3.5, 3.6 and $3.9 \mathrm{eV}$, respectively. With the increase in dopant size, crystallinity is reduced, and interchain separations and d-spacing are strengthened. The estimated conductivity values of PANI-PTSA, PANI-CSA, PANI-acetic acid and PANI-HCl are $3.84 \times 10^{1}, 2.92 \times 10^{1}, 2.50 \times 10^{-2}$, and $2.44 \times 10^{-2} \mathrm{~S} \cdot \mathrm{m}^{-1}$, respectively. Particularly, PANI-PTSA shows high PL intensity because of its orderly arranged benzenoid and quinoid units. Owing to its excellent synthesis, low bandgap, high photoluminescence intensity and high electrical features, PANI-PTSA is a suitable candidate to improve PANI properties and electron provider for fluorene-detecting sensors with a linear range of $0.001-10 \mu \mathrm{M}$ and detection limit of $0.26 \mathrm{nM}$.

Keywords: polyaniline; PANI; fluorene; dopant; PTSA; CSA; acetic acid; $\mathrm{HCl}$; XRD; conductivity; four-point probe; sensor; photoluminescence

\section{Introduction}

Fluorene is a polycyclic aromatic hydrocarbon (PAH) that poses risks to humans and the environment [1]. Several techniques have been developed for PAH detection, such as Fourier Transform Infrared spectroscopy, Raman spectroscopy, mass spectrometry (MS), gas chromatography (GC) and high-performance liquid chromatography [2]. Although these methods are sensitive and give reliable measurement, they are costly and require a long sample preparation time (non-real-time), bulky tabletop equipment and qualified operators. Others also suffer from low detection limits and necessitate a large amount of sample volume and solvent for separation and extraction.

Novel sensors for onsite fluorene detection, quantification and constant monitoring are vital to maintaining a healthy, non-polluted and sustainable environment. Technological growth in the field of sensors is driven by concerns about the safety and health of humanity [3]. Sensor devices are generally based on metal oxides operating at high temperatures. Hence, novel materials that can overcome the limitations of metal oxides are being explored. 
Polymer systems provide a new avenue to synthesize novel materials with high thermal, electrical and optical features. Conducting polymers have remarkably attracted interest in the fields of nanoscience and nanotechnology due to their exceptional conductivity and redox performance [4]. A conductive polymer is a polymer that exhibits semiconductor or even conductor properties by chemically or electrochemically doping its backbone with a conjugated double bond $[5,6]$. The main conductive polymers, such as p-phenylenevinylene (PPV), polypyrrole (PPy) and polyaniline (PANI), are being applied in many areas, including photothermal therapy, electromagnetic interference shielding, photovoltaic cell, storage battery, membrane gas separation, microwave absorption, chemical sensors and anti-corrosion coating [7-10]. Some of their advantages include improved interface qualities, suitability for the production of lightweight devices, affordability and high productivity $[10,11]$. In polymerization, a plain organic synthesis technique must be applied to achieve a repeatable macromolecular design.

PANI is a singular conducting polymer compound with unique electrical and optical properties [10] and has the advantages of simple synthesis, environmental stability, affordability and flexible control of electrical features with charge-transfer doping and protonation $[10,12,13]$. Owing to its extraordinary properties, this compound can be used in various fields, such as electrochromic glasses [14], solar cells [15], electroluminescent machines [10], sensors [16], biosensors [17], supercapacitors [18], neural prosthesis/biotic-abiotic interfaces [10], scaffolding [19], delivery systems [20], anti-corrosion materials [21], membrane gas separation [8] and solar cells [22]. During the polymerization of aniline monomer, PANI transforms into one of the three states of normalized oxidation: (a) leucoemeraldine (white/clear), (b) pernigraniline (blue/violet) and (c) emeraldine (salt- green/base-blue). Pernigraniline is a completely oxidized PANI, emeraldine is half evenly oxidized and half decreased PANI, and leucomeraldine is completely decreased PANI [23]. The most conductive and consistent state is emeraldine with the conductivity of less than $10^{-10} \mathrm{~s} \mathrm{~cm}^{-1}$ created by its salt form. The synthesis method affects the conductivity of PANI, which can be controlled by immersing the emeraldine base in an aqueous acidic solution. PANI generally assumes a dark green solid-state after being formed through oxidative chemical polymerization inside an acidic aqueous average $[10,24]$ in a solution of phosphoric acid, picric acid or camphor sulfonic acid [25-28].

In the presence of an acid, PANI synthesis initially occurs through bipolar formation, followed by the development of a polar shape (Figure 1) [29-33]. The formation of a polaron structure leads to PANI-ES using protonation. Electrification of a conducting polymer causes the dopant to begin moving along the polymer; this phenomenon leads to the steady-state impairment because polarons can move along the polymer chains to enable electrical conductivity [34]. Doping either removes the electrons from the valence band molecular orbital or transfers them to the last empty transmission band molecular orbital. This process produces charge carriers, including polar and bipolar, inside the polymer $[35,36]$. The charge carriers of the polaron generate energy inside the dopantrestricted energy band to enable electron transfer from the valence to the conduction band.

PANI has a high potential to capture PAHs, such as fluorene that contains aromatic rings and a carboxyl functional group that can interact with PANI [37]. This compound also has promising chemical and physical properties such as high conductivity, environmental stability, corrosion resistance and homogenous microstructure. Additionally, PANI has functional groups such as sulfonated poly (aniline-co-o-aminophenol) and s-copolymer and can be prepared using oxidative chemical methods and doped with different acids [38]. Therefore, PANI is a suitable conductive polymer for PAH detection. Investigating the interaction of PANI with PAHs can help improve the fundamental understanding and application of PANI in sensors. 


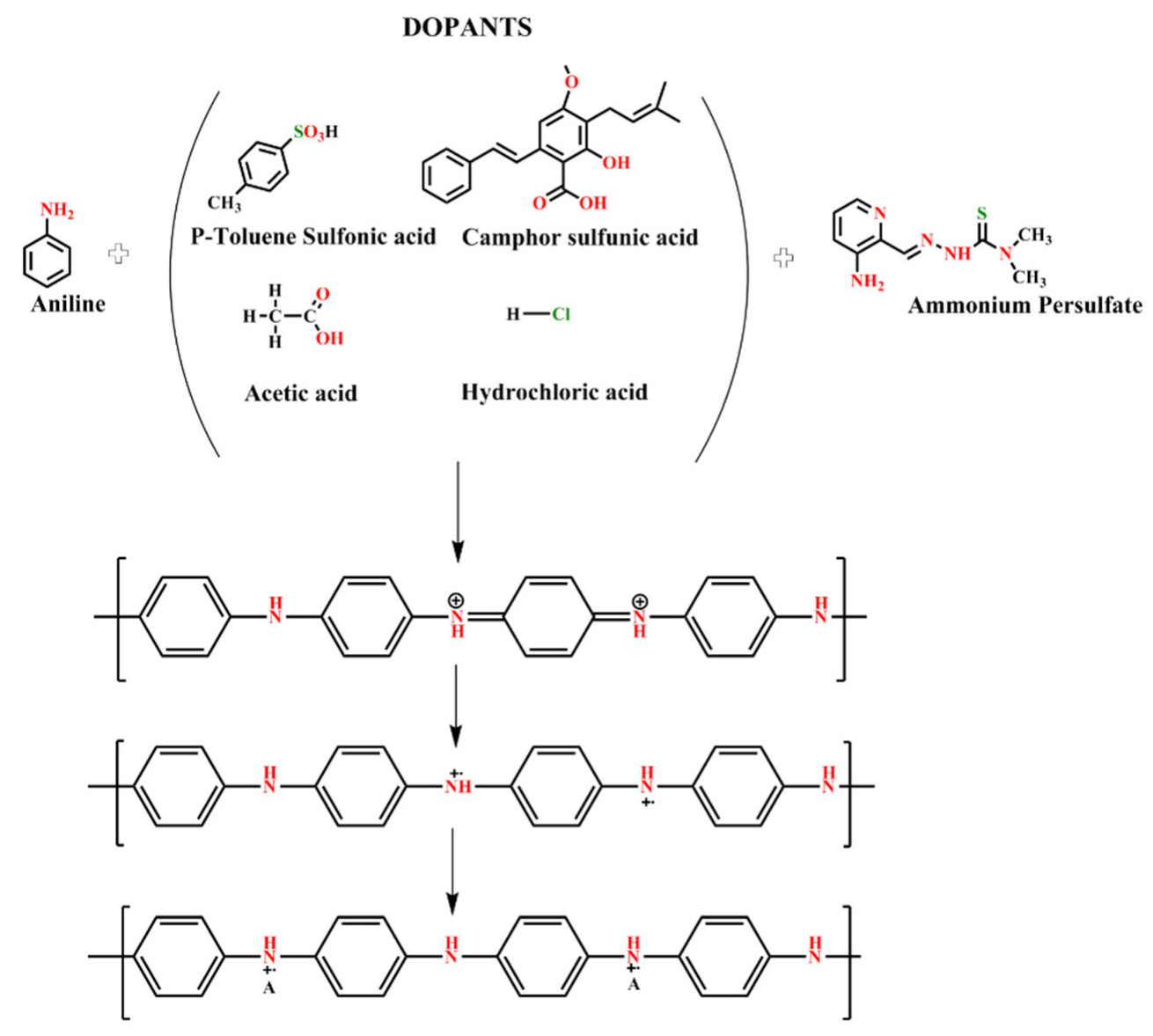

Figure 1. Synthesis of PANI by using different acids as dopants.

In this study, the effects of different acids as dopants on the physical properties and thermal, optical and electrical qualities of PANI were investigated. PANI was prepared through oxidative polymerization and doped using four types of acid, namely, organic acids such as toluene-4-sulfonic acid monohydrate (PTSA), camphor sulfonic acid (CSA) and acetic acid and inorganic acids such as hydrochloric acid $(\mathrm{HCl})$. The prepared samples were examined by Fourier transform infrared (FT-IR) spectroscopy, X-ray diffraction (XRD), UV-visible spectroscopy (UV-vis), field emission scanning electron microscopy (FE-SEM), energy dispersive $\mathrm{X}$-ray spectrometry (EDS), thermal gravity analysis (TGA) and photoluminescence (PL). The four-point probe method was used to investigate electrical behavior, and photoluminescence spectroscopy was applied to detect fluorescence properties. The application of PANI with excellent synthesis, features and high PL intensity to detect low fluorene concentration was also evaluated.

\section{Materials and Methods}

\subsection{Materials}

PTSA, aniline monomer (aniline 99\%), CSA, hexane and fluorene were purchased from Merck KGaA, Darmstadt, Germany. N-Methyl-2-pyrrolidone, ammonium persulfate (APS $98 \%$ ), acetic acid, $\mathrm{HCl}$, ammonia solution $\left(\mathrm{NH}_{4} \mathrm{OH}\right)$ and $\mathrm{H}_{2} \mathrm{O}_{2}$ were provided by Avanti Chemicals of Merck KGaA, Darmstadt, Germany. Microscope glass slides were acquired from Jiangsu Huida Medical Instruments Co., Ltd. (Yancheng, Jiangsu, China). All chemicals were of analytical grade. Distilled water was used for aniline synthesis.

\subsection{Preparation of PANI}

PANI was synthesized as previously described [39]. Briefly, $2.75 \mathrm{~mL}$ of aniline was dissolved in $150 \mathrm{~mL}$ of $0.4 \mathrm{M}$ PTSA, constantly stirred for $1 \mathrm{~h}$, cooled and dropwise added 
with $25 \mathrm{~mL}$ of APS (1.7 $\mathrm{g}$ of APS dissolved in $25 \mathrm{~mL}$ of $0.4 \mathrm{M}$ PTSA). The temperature was kept at $0-5{ }^{\circ} \mathrm{C}$ in an ice bath. The mixture was stirred for another $3 \mathrm{~h}$. The precipitated raw polymer was filtered and washed using deionized water until it became colorless. The final substance was dehydrated in an oven at $50{ }^{\circ} \mathrm{C}$ for $12 \mathrm{~h}$. In this form, PANI is known as emeraldine salt (ES). PANI was re-synthesized with three organic (CSA and acetic acid) and inorganic $(\mathrm{HCl})$ acids (Table 1$)$.

Table 1. Preparation of PANI samples.

\begin{tabular}{ccccc}
\hline Sample Name & $\begin{array}{c}\text { Aniline Monomer } \\
\text { Concentration }(\mathbf{m L})\end{array}$ & $\begin{array}{c}\text { APS as Oxidant } \\
\text { Monomer } \mathbf{( g )}\end{array}$ & Different Acids (0.4 M) & Weight of the PANI (g) \\
\hline PANI-PTSA & 2.75 & 1.7 & PTSA & 0.2 \\
PANI-CSA & 2.75 & 1.7 & CSA & 0.18 \\
PANI-Acetic acid & 2.75 & 1.7 & Acetic acid & 0.15 \\
PANI-HCl & 2.75 & 1.7 & HCl & 0.19 \\
\hline
\end{tabular}

\subsection{Preparation of Fluorene}

PANI-PTSA with fluorene was prepared as follows. Briefly, $0.002 \mathrm{~g}$ of fluorene was dissolved in $250 \mathrm{~mL}$ of hexane containing $10 \mu \mathrm{M}$ of fluorene solution to prepare aqueous fluorene solution. Other concentrations, i.e., $0.001,0.01,0.1,1$ and $10 \mu \mathrm{M}$ were obtained by diluting the $10 \mu \mathrm{M}$ fluorene solution as mentioned in Table 2 . In all samples, fluorene amount was set as $160 \mu \mathrm{L}$.

Table 2. Preparation of PANI-PTSA with fluorene concentrations.

\begin{tabular}{cccc}
\hline Sample Name & Amount of PANI* $(\mu \mathbf{L})$ & Amount of Fluorene $(\mu \mathrm{L})$ & Fluorene Concentrations $(\mu \mathbf{M})$ \\
\hline PANI-PTSA-fluorene-1 & 2900 & 100 & 0.001 \\
PANI-PTSA-fluorene-2 & 2900 & 100 & 0.01 \\
PANI-PTSA-fluorene-3 & 2900 & 100 & 0.1 \\
PANI-PTSA-fluorene-4 & 2900 & 100 & 1 \\
PANI-PTSA-fluorene-5 & 2900 & 100 & 10 \\
\hline
\end{tabular}

\subsection{Preparation of Thin Film}

For the preparation of thin PANI layers, microscope glass slides were sonicated in ethanol for $10 \mathrm{~min}$, then immersed in an aqueous solution of $4.0 \mathrm{~mL}$ of $\mathrm{H}_{2} \mathrm{O}_{2}, 4.0 \mathrm{~mL}$ of $\mathrm{NH}_{4} \mathrm{OH}$ and $20.0 \mathrm{~mL}$ of deionized water for another $10 \mathrm{~min}$, sonicated in deionized water and finally dried naturally. PANI solution with different dopants was adjusted to $80 \mu \mathrm{L}$. The thin film was deposited above a glass substrate by applying a spin coater (POLOS) at approximately $1500 \mathrm{rpm}$ for $60 \mathrm{~s}$. The remaining dispersions were stored in a safe place and monitored after $24 \mathrm{~h}$.

\subsection{Analytical Methods}

FT-IR spectroscopy (Thermo Nicolet 6700 FT-IR) with $\mathrm{KBr}$ pellets was conducted in the range of $400-4000 \mathrm{~cm}^{-1}$ to categorize the functional groups and surface state of the PANI samples. X-ray diffraction (XRD) images were obtained by Shimadzu $6000 \mathrm{using} \mathrm{Cu}-\mathrm{K} \alpha$ radiation at a scanning speed of $1.2^{\circ} \mathrm{min}^{-1}$ of 3 to 90 degrees to ascertain the purity phase. Optical characteristics were determined by UV-vis spectroscopy (UV-vis, Lambda 35, PerkinElmer) at ambient temperature. Morphology was examined using a field emission scanning electron microscope (FE-SEM, NOVA NANOSEM 230). X-ray energy dispersive spectroscopy (EDS) was employed to determine the elemental composition of specific points or record the lateral distribution of elements in the imaged region. TGA analysis was adopted to study the thermal stability of the PANI samples below a nitrogen atmosphere from ambient temperature up to $900{ }^{\circ} \mathrm{C}$ at a heat range of $10^{\circ} \mathrm{C} / \mathrm{min}$ (Brand: METTLER TOLEDO). The photoluminescence excitation and emission wavelengths of 230 and $370 \mathrm{~nm}$, respectively, were recorded in an aqueous solution utilising photoluminescence settings 
(PL, PerkinElmer, and LS 55). Electrical conductivity was measured using a four-terminal probe from Mitsubishi Chemical Analytech (MCCAT) Measuring Systems.

\section{Result and Discussion}

\subsection{FT-IR Characterization}

The components of PANI samples were examined by FT-IR analysis at $500-4000 \mathrm{~cm}^{-1}$. Figure 2 displays that doping with various acids effectively alters the PANI environment. All PANI samples are mainly of the same structure but still show significant differences from each other. The prominent vibrational bands shown in Table 3 are consistent with those previously reported for PANI salt [39].
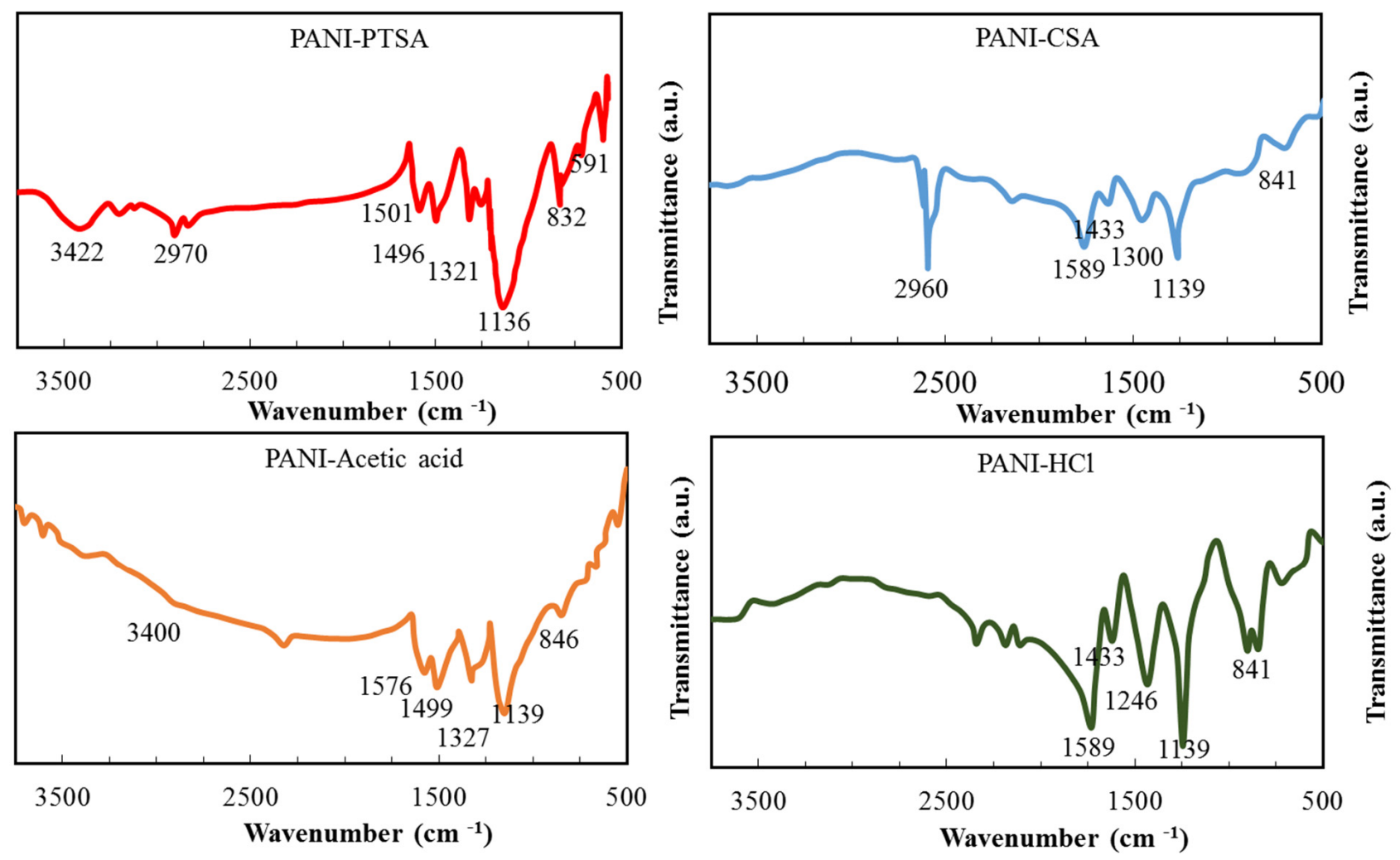

Figure 2. FT-IR spectra of synthesized PANI samples.

Table 3. Comparison of functional group peaks in the FT-IR spectra of the PANI samples.

\begin{tabular}{lccccc}
\hline Assignment & & PANI-PTSA [39] & PANI-CSA [40] & PANI-Acetic Acid [41,42] & PANI-HCl [40] \\
\hline Symmetric and asymmetric & $\mathrm{NH}_{2}$ and NH & 3422 & - & 3400 & - \\
stretching & $\mathrm{C}-\mathrm{H}$ and $\mathrm{CH}_{2}$ & 2970 & 2960 & - & - \\
Aromatic aniline ring & $\mathrm{C}=\mathrm{C}$ & 1501 & 1589 & 1576 & 1439 \\
Quinoid ring stretching & $\mathrm{N}-\mathrm{B}-\mathrm{N}$ & 1496 & 1300 & 1327 & 1433 \\
Benzonoid ring stretching & $\mathrm{C}-\mathrm{N}$ & 1321 & 1139 & 1139 & 1246 \\
C-N stretching of benzenoid ring & $\mathrm{C}-\mathrm{H}$ & 1136 & 841 & 846 & 841 \\
In-plane bending vibration of C-H & $\mathrm{C}-\mathrm{H}$ & 832,591 & & \\
Ortho substitutions, 1,2 & & & & & \\
disubstitution in benzene ring & & &
\end{tabular}

The peaks for PANI-PTSA and PANI-HCl are sharper than those for PANI-CSA and PANI-acetic acid. Protonation converts PTSA and $\mathrm{HCl}$ to imine and amine nitrogen atoms, respectively, in PANI-PTSA and PANI-HCl structures, respectively. Benzenoid's FT-IR absorption peaks and quinoid stretching fluctuations can predict the oxidation degree $[39,40]$. The peaks for PANI samples in Table 3 are consistent with those in previous reports [39-42]. 
In PANI-CSA and PANI-PTSA, the peaks at 2960 and $2970 \mathrm{~cm}^{-1}$ are associated with $\mathrm{C}-\mathrm{H}$ stretching. These bands are not affected by doping, indicating that an aromatic ring is preserved inside the polymer [40].

\subsection{XRD Characterization}

Figure 3 presents the XRD pattern of PANI doped with different acids, and Table 4 summarises their peak values. As indicated by differences in their diffraction patterns, the doping abilities of the dopants significantly vary under the same doping conditions. A broad diffraction pattern is obtained for all PANI samples due to their typical amorphous nature. XRD helps in estimating the size of inter-chain disconnection, crystallinity, crystallite size and d-spacing.
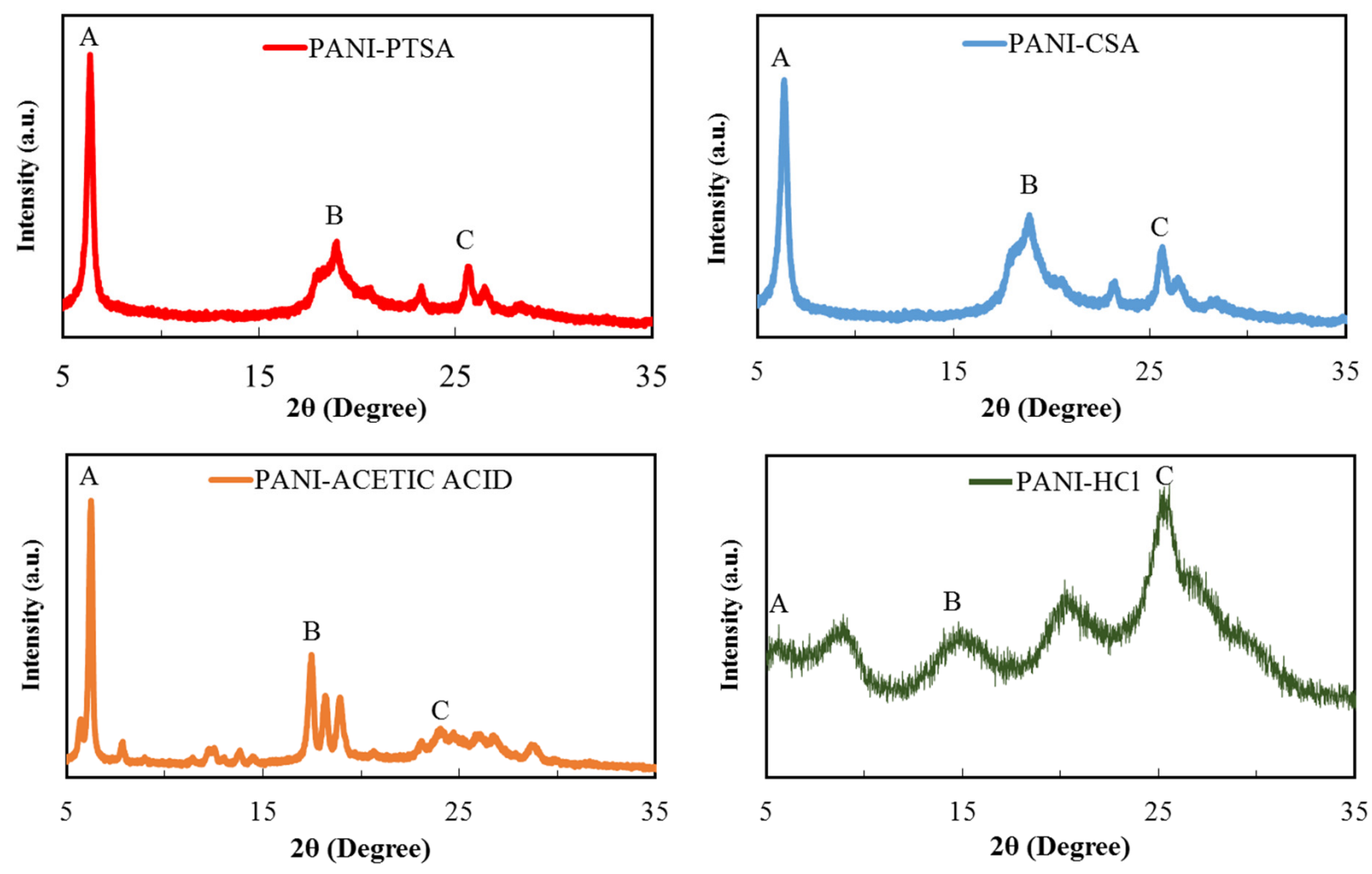

Figure 3. XRD spectra of synthesized PANI samples.

Table 4. Crystallite size, d-spacing and interchain division of PANI samples exposed over various shots of ES reflection (measured from XRD).

\begin{tabular}{|c|c|c|c|c|c|}
\hline Sample Name & Peak Sign & d-Spacing ( $\mathrm{A})$ & FWHM (B) & Crystallite Size (nm) & $\begin{array}{l}\text { Inter-Chain } \\
\text { Separation (Å) }\end{array}$ \\
\hline PANI-PTSA-1 & $\mathrm{A}$ & 15.71429 & 0.006 & 241.750167 & 19.64285714 \\
\hline PANI-PTSA-2 & $\mathrm{B}$ & 4.695122 & 0.044 & 33.36713996 & 5.868902439 \\
\hline PANI-PTSA-3 & C & 3.484163 & 0.017 & 87.33634992 & 4.35520362 \\
\hline PANI-CSA-1 & A & 14.25926 & 0.008 & 181.3126253 & 17.82407407 \\
\hline PANI-CSA-2 & $\mathrm{B}$ & 4.723926 & 0.051 & 28.78733644 & 5.904907975 \\
\hline PANI-CSA-3 & $\mathrm{C}$ & 3.494163 & 0.027 & 59.56613339 & 4.36520362 \\
\hline PANI-Acetic acid-1 & $\mathrm{A}$ & 14.5283 & 0.004 & 362.6252505 & 18.16037736 \\
\hline PANI-ACETIC acid-2 & $\mathrm{B}$ & 5.099338 & 0.02 & 72.5250501 & 6.374172185 \\
\hline PANI-ACETIC acid-3 & $\mathrm{C}$ & 3.615023 & 0.0249 & 54.98955366 & 4.375 \\
\hline PANI-HCl-1 & A & 16.04167 & 0.037 & 39.20272978 & 20.05208333 \\
\hline PANI-HCl-3 & B & 5.968992 & 0.091 & 16.05216176 & 7.46124031 \\
\hline PANI-HCl-5 & $\mathrm{C}$ & 3.5 & 0.107 & 13.87586868 & 4.518779343 \\
\hline
\end{tabular}


For all samples, d-spacing was delimited using Debye-Scherrer (powder) method utilizing the Bragg relation (Equation (1)) [43].

$$
n \lambda=2 d \sin \theta,
$$

where $n$ is an integer; $\lambda$ is the wavelength of X-ray, which for the Cu target is $1.54 \AA$; $d$, named as $d$-spacing, is the distance among the planes; and $\theta$ is the angle between the path of the beam and the planes.

Crystallite quantity was measured using the Scherrer relation (Equation (2)) [44];

$$
t=\frac{k \lambda}{B \cos \theta},
$$

where $t$ is the crystallite quantity, $K$ is the ordinary crystallite $(\sim 0.9)$ the shape factor and $B$ is the entire diameter at crystalline peak's half maximum in radians [45].

Inter-chain separation was determined using the relation given by Klug and Alexander (Equation (3)):

$$
R=\frac{5 \lambda}{8 \sin \theta},
$$

where $R$ is the inter-chain division.

The XRD profile for the PANI-PTSA pattern includes broad peaks at $6.4^{\circ}$ and $18.97^{\circ}$ and a sharp peak at $25.64^{\circ}$. The peak at $18.97^{\circ}$ indicates the inter-chain distance between adjoining benzene rings in PANI, and the peak at $25.64^{\circ}$ is attributed to the dispersion of PANI chains at an interplanar distance. On the basis of this microstructural analysis, PANI is in the verified form of ES [46]. PANI-CSA also shows similar peaks at $6.35^{\circ}$ and $18.86^{\circ}$ and a sharp peak at $25.61^{\circ}$ [40]. PANI-acetic acid shows sharp, intense peaks at $6.26^{\circ}$, $17.49^{\circ}$ and $24.72^{\circ}$ attributed to the arrangement of the acetic acid molecules in the tunnels between the PANI chains [47]. Finally, PANI- $\mathrm{HCl}$ shows five peaks at $5.65^{\circ}, 9.05^{\circ}, 14.92^{\circ}$, $20.62^{\circ}$ and $25.55^{\circ}[48,49]$. Given its long alkyl tails, PTSA can penetrate the crystal planes of PANI deeper than other acids with bulky cycloaliphatic rings such as CSA, acetic acid and $\mathrm{HCl}$.

As shown in Table 4, all PANI samples have three crystalline peaks at $6^{\circ}, 18^{\circ}$ and $25^{\circ}$. Conductivity increases with the increasing crystallinity and decreasing inter-chain spacing and d-spacing. Table 5 describes the main properties of PANI samples obtained from the peak at $25^{\circ}$ in the XRD characterization and their comparison with those from other research. A high grade of balance in the organization or order of polymer chains implies great crystallinity. Balance and ordered construction, defined as crystallinity, is a desirable factor, particularly for the intra-molecular movement of charged varieties towards the chain and to any degree for inter-molecular jumps due to dense and good packing. Therefore, an increase in crystallinity also increases conductivity. When the inter-chain spacing and d-spacing decrease, the possibility of inter-chain jumps increases, and conductivity simultaneously increases. Net conductivity is attributed to the intra-chain and inter-chain mobility of the electrons and holes [50,51]. Crystallinity reduction is in the order of PANI-PTSA > PANI-CSA > PANI-acetic acid > PANI-HCl. The actual quantity of inter-chain separation and d-spacing is the exact opposite of the theoretical quantity. Hence, conductivity decreases in the following order: PANI-PTSA > PANI-CSA > PANI-acetic acid $>$ PANI-HCl. Nonetheless, the large acid exerts great force against the ordering and closing of polymer chains, resulting in low crystallinity, great inter-chain spacing and d-spacing and reduced conductivity. 
Table 5. Features of synthesized PANI samples and comparison with other research.

\begin{tabular}{|c|c|c|c|c|c|c|}
\hline Sample Name & $\begin{array}{l}\text { Crystallite Size } \\
\text { (nm) }\end{array}$ & d-Spacing (Å) & $\begin{array}{l}\text { Inter-Chain } \\
\text { Separation (A) }\end{array}$ & Bandgap & $\begin{array}{l}\text { Conductivity } \\
\left(S \cdot \mathrm{cm}^{-1}\right)\end{array}$ & References \\
\hline \multirow{4}{*}{ PANI-PTSA } & 47 & 3.50 & 4.37 & 4.50 & $4.8 \times 10^{-2}$ & [30] \\
\hline & 13.8 & 3.51 & 4.39 & 4.196 & $1 \times 10^{-2}$ & [50] \\
\hline & 29 & 4.6 & - & - & $12 \times 10^{-2}$ & [46] \\
\hline & 87 & 3.48 & 4.35 & 3.1 & $3.84 \times 10^{1}$ & Current study \\
\hline \multirow{4}{*}{ PANI-CSA } & - & 3.52 & - & 3.8 & $11 \times 10^{-2}$ & [52] \\
\hline & 65 & 4.9 & - & - & $21 \times 10^{-2}$ & [46] \\
\hline & 56 & - & - & - & $2.7 \times 10^{1}$ & [40] \\
\hline & 59 & 3.49 & 4.36 & 3.5 & $2.92 \times 10^{1}$ & Current study \\
\hline \multirow{4}{*}{$\begin{array}{l}\text { PANI-Acetic } \\
\text { acid }\end{array}$} & 49 & - & - & - & $6.5 \times 10^{-2}$ & [53] \\
\hline & - & - & - & - & $4.21 \times 10^{-2}$ & [32] \\
\hline & - & - & - & - & $6.5 \times 10^{-5}$ & [54] \\
\hline & 55 & 3.6 & 4.37 & 3.6 & $2.50 \times 10^{-2}$ & Current study \\
\hline \multirow{4}{*}{ PANI-HCl } & 59 & 3.49 & 4.36 & 4.48 & $1.6 \times 10^{-1}$ & [30] \\
\hline & - & - & - & 2.40 & $54 \times 10^{-2}$ & [55] \\
\hline & 38.3 & 3.9 & - & 3.85 & - & [56] \\
\hline & 14 & 3.5 & 4.5 & 3.9 & $2.44 \times 10^{-2}$ & Current study \\
\hline
\end{tabular}

\subsection{UV-Vis Characterization}

Figure 4 shows the UV-vis spectra of PANI samples. The absorption peaks of PANI samples depend on the doping level, conjugation extent and solvent type [57]. Valance and conduction bands are formed by the $\pi$ and $\pi^{*}$ orbital, respectively.

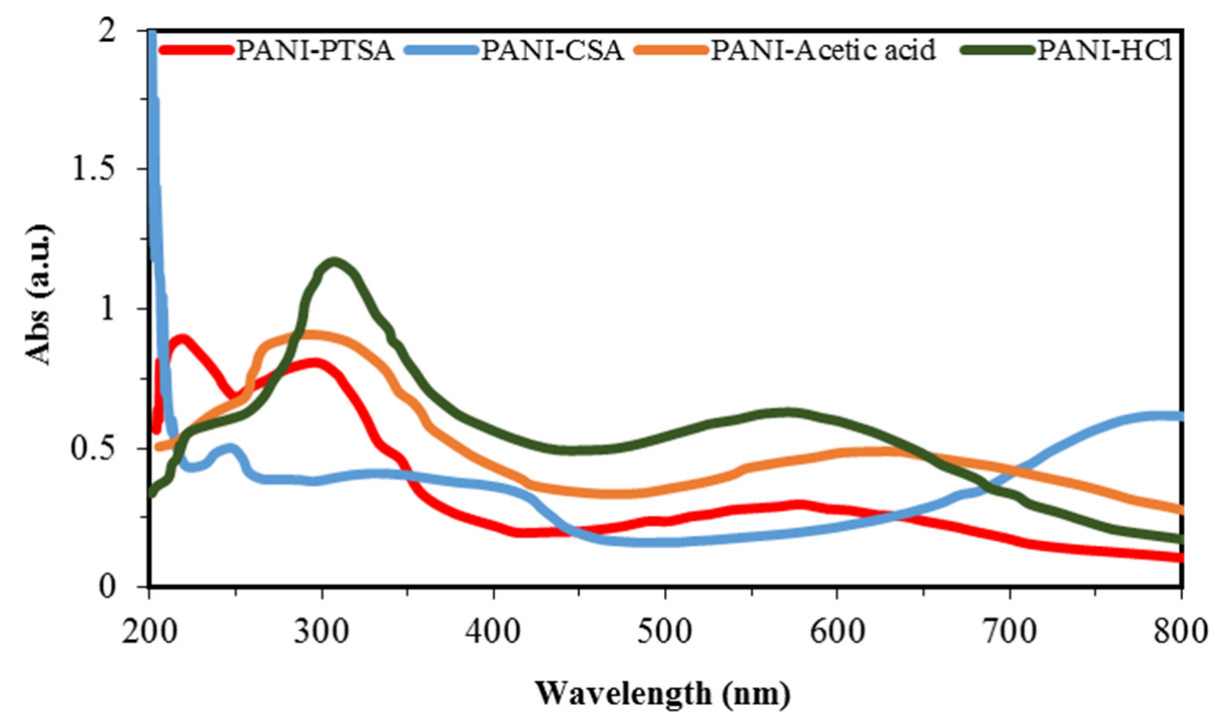

Figure 4. UV-vis spectra of synthesized PANI samples.

Bandgaps are energy variations between two bands and are used to determine the optical properties of semiconducting polymers. Low bandgap energy implies smooth $\pi-\pi^{*}$ electronic transformation and increased conductivity [58]. The UV spectra of PANI samples exhibit three specific absorption bands across the wavelength regions of 250-320, 320-450 and $450-800 \mathrm{~nm}$. Nitrogen excitation in the benzenoid segments ( $\pi-\pi^{*}$ transition) causes the first absorption, and the shift from polaron to $\pi^{*}$ band and from $\pi$ to polaron band of the doped PANI chains causes the second and third absorptions, respectively [53,58-60]. Table 6 shows the comparison of absorption rates from the UV-vis spectra of PANI samples. A decrease in absorption band at 578, 579 and $630 \mathrm{~nm}$ occurs for PANI-PTSA, PANI-HCl, and PANI-acetic acid, respectively. This phenomenon indicates that the quinoid rings and 
imine nitrogen atoms generated from protonation with PTSA, $\mathrm{HCl}$ and acetic acid dopants are transformed to benzenoid rings. The steric effect of the dopant anions may be the reason for the decrease in the peaks at 570 and $630 \mathrm{~nm}$ of the PANI samples [55].

Table 6. Comparison of the absorbance values of the PANI samples.

\begin{tabular}{cccccc}
\hline \multicolumn{2}{c}{$\Pi-\pi^{*}$} & \multicolumn{2}{c}{ Polaron to $\pi^{*}$} & \multicolumn{2}{c}{$\pi$ to Polaron } \\
\hline PANI-Samples & Wavelength $(\mathbf{n m})$ & PANI-Samples & Wavelength $(\mathbf{n m})$ & PANI-Samples & Wavelength (nm) \\
\hline PANI-PTSA & 207 & PANI-PTSA & 321 & PANI-PTSA & 578 \\
PANI-CSA & 253 & PANI-CSA & 338 & PANI-CSA & 785 \\
PANI-Acetic acid & 283 & PANI-Acetic acid & - & PANI-Acetic acid & 630 \\
PANI-HCl & 317 & PANI-HCl & - & PANI-HCl & 579 \\
\hline
\end{tabular}

Diffuse reflectance was analyzed to ascertain the energy range and the optical features of the PANI samples. Bandgap energies were calculated using the Tauc method, in which the energy-dependent absorption coefficient $\alpha$ is obtained using the following Equation (4):

$$
(\alpha h v)^{2}=K(h v-E g),
$$

where $v$ is the frequency of the photon, $h$ is Planck's constant, $E g$ is the bandgap energy, $K$ is a constant and $\alpha$ is the diffuse reflectance spectrum calculated from Equation (5):

$$
F(R)=\frac{1-R}{2 R} .
$$

Substituting $F(R)$ in place of $\alpha$ in Equation (1) yields Equation (6):

$$
(F(R) \cdot h v)^{2}=K(h v-E g),
$$

where $R$ is the recognized reflectance inside UV-vis spectra, the crossing position within the $[F(R) . h v]^{2}$ versus $h v$ (Figure 5) implies that the bandgaps are an optical feature that can be calculated by extrapolating the straight line at $\alpha=0$. Therefore, the calculated optical bandgaps of PANI-PTSA, PANI-CSA, PANI-acetic acid and PANI-HCl were 3.1, 3.5, 3.6 and $3.9 \mathrm{eV}$, respectively. Laboratory experiment confirmed that the PANI bandgap differs significantly depending on the doping process. With increasing interaction between PANI and doping anions PTSA, CSA, acetic acid, and $\mathrm{HCl}$ and BSA, the conductivity of particles and the number of charge carriers increase, whereas the amount of bandgap decreases (Table 5).

\subsection{FE-SEM and EDS Characterization}

PANI morphology relies on the synthesis method, medium or solvent [61]. Figure 6 shows the FE-SEM images and elemental analysis of PANI samples prepared by using oxidative aniline polymerization techniques in organic and inorganic acid solutions. High surface tension is observed, leading to an aggregation tendency and a low specific surface area [62]. All the figures present the micrographs of PANI particles at a magnification of 10,000 with a scale bar of $2 \mu \mathrm{m}$. A granular structure (cluster) with micrometer-sized particles is found on the PANI surface, thus confirming the formation of ES [62]. By contrast, large aggregates of PANI particles with up to several microns in size are formed after drying as shown in FE-SEM images. Nanofibres are generally the fundamental units produced during the oxidative chemical polymerization of PANI [63-65]. Owing to secondary overgrowth, the generated final products become irregularly shaped PANI powders. Although the chemical polymerization of aniline can prevent secondary growth [66], aggregation remains crucial in this case. Agglomeration occurs due to the intra- and intermolecular ionic interchain interactions triggered by the proto-generated charge carriers (i.e., polarons / bipolarons) [67]. PANI-PTSA, PANI-CSA and PANI-acetic acid exhibit fi- 
brous crystals when compressed. Meanwhile, PANI-HCl forms agglomerated ball crystals because the molecular chain stretches along the direction of mixing and shear forces during polymer crystallization [68].
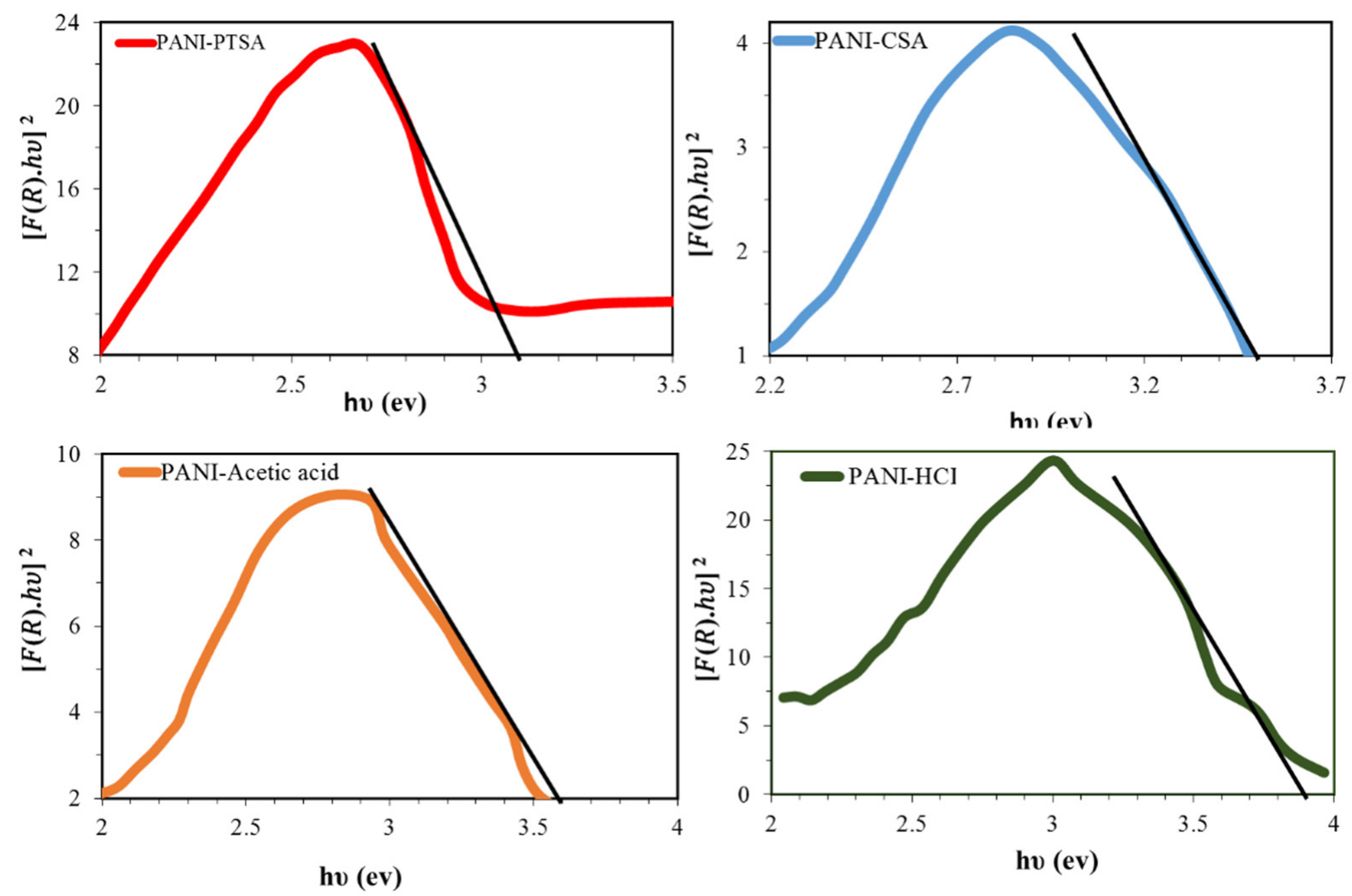

Figure 5. Bandgap curves as optical properties of the PANI samples.

The EDS results provide an explicit indication of the doped elements in the PANI samples. Chlorine $(\mathrm{Cl})$ was generated from PANI doped by $\mathrm{HCl}$. The importance of sulfur in the EDX pattern is because of using APS as an oxidant in polymerization.

\subsection{TGA Characterization}

TGA was conducted to assess the thermal stability of the PANI synthesized in different acids, as shown in Figure 7, PANI-PTSA, PANI-CSA, PANI-acetic acid, and PANI-HCl. The mass losses were studied when heated in a nitrogen atmosphere. TGA curves for all samples show almost three regions of weight loss. In PANI-PTSA, the loss at around $108^{\circ} \mathrm{C}$ is due to the elimination of moisture and other volatile compounds $[69,70]$. The second region starting at approximately $275^{\circ} \mathrm{C}$ could be due to the loss of PTSA in the product [71]. The third region starting at approximately $391{ }^{\circ} \mathrm{C}$ could be due to the degradation of PTSA bonds [39].

Figure 7 shows that PANI-CSA and PANI-HCl exhibit almost three weight loss regions, particularly a weight loss at $<120^{\circ} \mathrm{C}$ caused by the evaporation or excretion of the imbibed water. Thus, moisture cannot be completely removed from the samples throughout the synthesis [72]. The second weight loss in PANI- $\mathrm{HCl}$ at $250{ }^{\circ} \mathrm{C}$ is due to the evaporation of $\mathrm{HCl}$ molecules.

This intermediate, relatively small decomposition stage is discerned in PANI-CSA. The process begins at $286^{\circ} \mathrm{C}$ and extends to $500{ }^{\circ} \mathrm{C}$, after which a rapid decomposition occurs. Although the intermediate stage of degradation is highly evident with $\mathrm{HCl}$ doping at $490{ }^{\circ} \mathrm{C}$, this phenomenon is also observed for PANI-CSA near $\sim 502{ }^{\circ} \mathrm{C}$, which represents the ultimate disintegration related to the polymer backbone. All the doped samples exhibit 
low disintegration temperature and low thermal resistance, except for the plasticized PANI-HCl with high estimated thermal stability [73].

Figure 7 shows the shape of the TGA thermograms for PANI-acetic acid. Solvent evaporation was conducted to purify the composites, and this procedure causes the first weight loss. Oligomer degradation causes the second weight loss (between $296^{\circ} \mathrm{C}$ and $317^{\circ} \mathrm{C}$ ), and the evaporation of the sample causes the third weight loss of PANI-acetic acid [53].
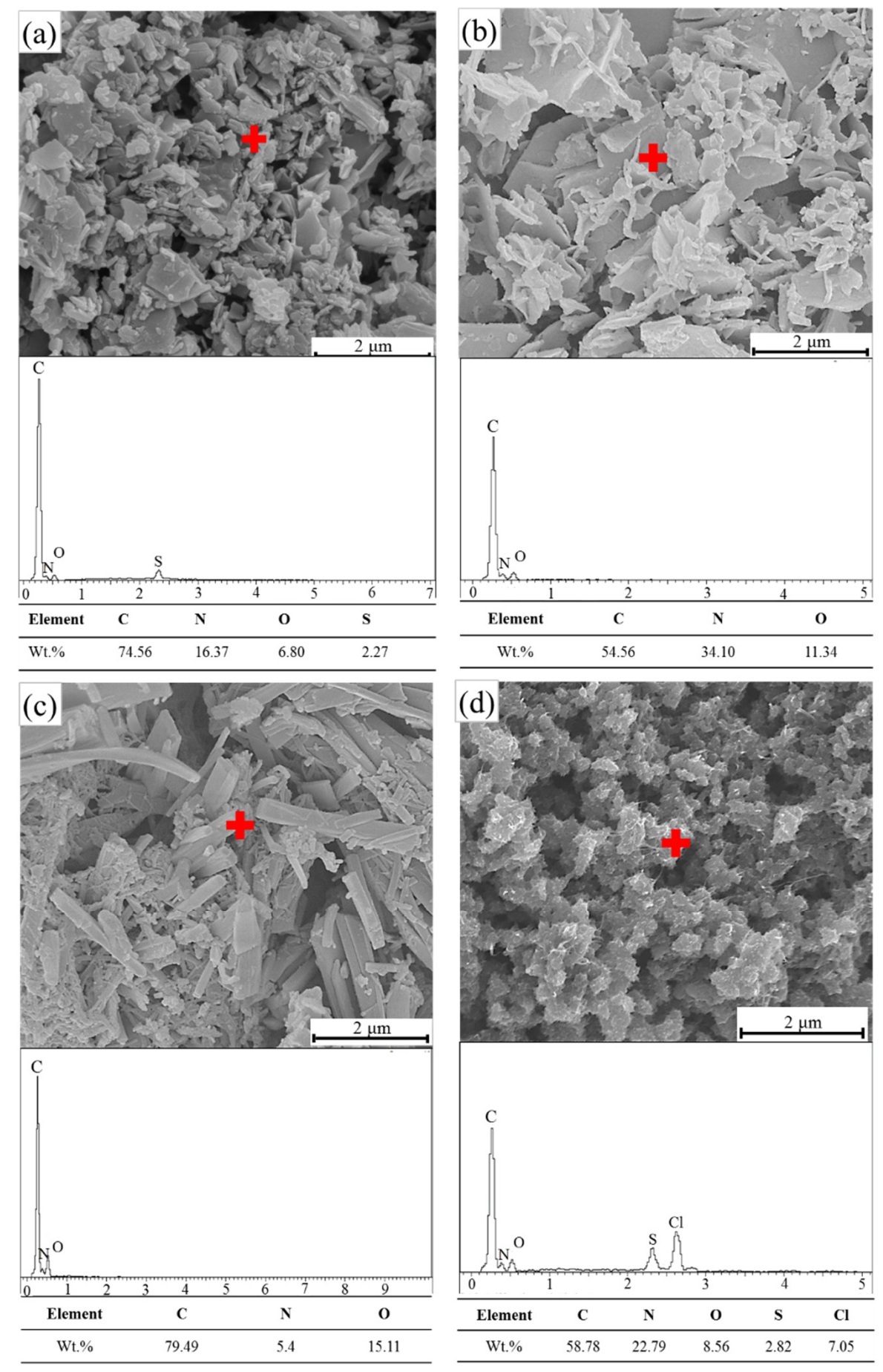

Figure 6. FE-SEM patterns and EDS point analysis of (a) PANI-PTSA, (b) PANI-CSA, (c) PANI-acetic acid and (d) PANI-HCl. 


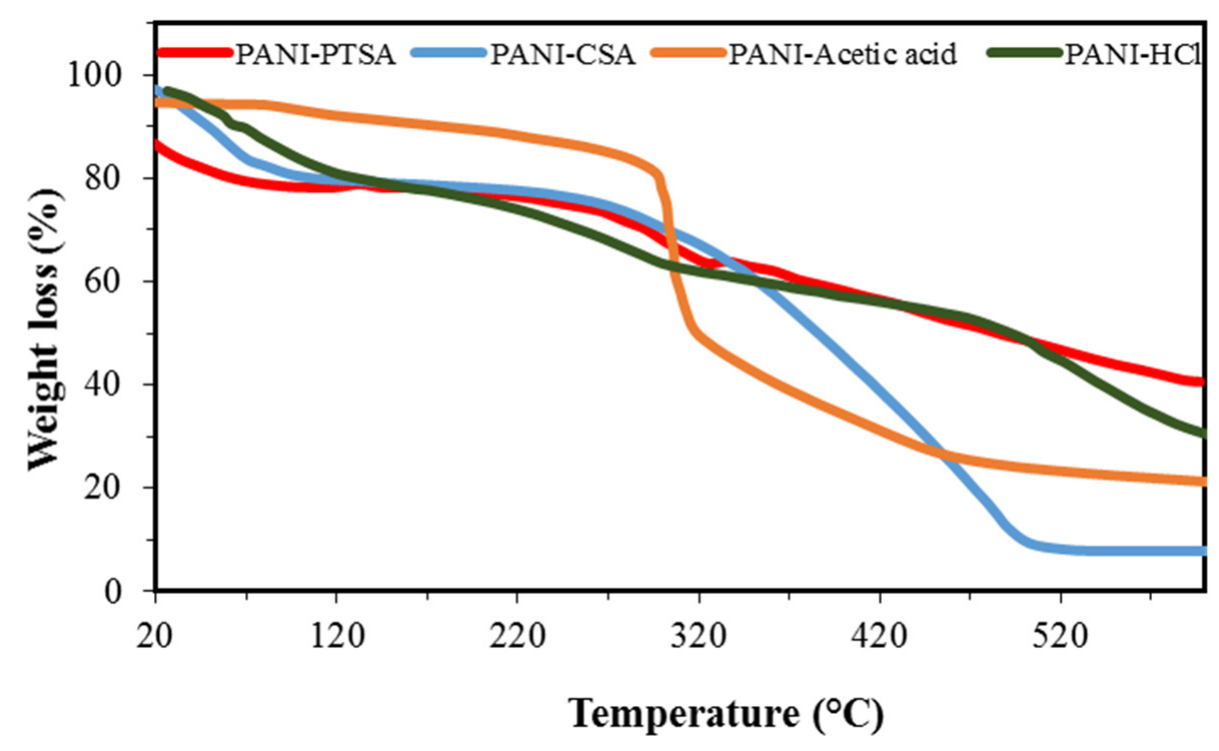

Figure 7. TGA spectra of synthesized PANI samples.

PANI amount determines the thermal stability of the prepared composites. TGA results showed that acidity affects the thermal stability of PANI.

\subsection{PL Analysis}

Figure 8 shows the measured PL spectra for the four samples. Excitation and emission wavelengths of 230 and $370 \mathrm{~nm}$ were chosen because the $\pi-\pi^{*}$ transition of benzenoid units is responsible for PL in PANI [74]. As shown in Figure 8a, the excitation peaks for all samples were observed at $258 \mathrm{~nm}$, except for PANI-HCl with a peak at $264 \mathrm{~nm}$. As shown in Figure 8b, the emission peaks for all samples were located at $326 \mathrm{~nm}$, except for PANI-HCl with a peak at $316 \mathrm{~nm}$. The PL intensity of PANI-HCl could be attributed to the appearance of few dopant ions $(\mathrm{Cl}-)$ in PANI-HCl that have greater charge mobility than the heavy dopant ions in other samples [73].

PANI-PTSA shows the highest PL intensity, followed by PANI-CSA, PANI-acetic acid and PANI-HCl. In PANI-PTSA, the benzenoid and quinoid parts are orderly arranged and thus support the formation of excitons and the enlargement of singlet exciton's delocalization length $[74,75]$. Therefore, a high photoluminescence emission with a great extent of $\pi$ conjugation should be expected from PANI-PTSA.

\subsection{Electrical Analysis}

A four-point probe was used to determine the conductivity of PANI samples at room temperature. The voltage difference can be observed when a current flows through the test specimen. Conversely, the resistance to current flow indicates conductivity.

Two parameters are crucial in PANI conductivity. One is the degree of oxidation, and the other is the degree of protonation [76]. The properties of PANI depend on the polymerization conditions ( $\mathrm{pH}$, temperature and time), monomer concentration, dopant type, the molar ratio of monomer to oxidant and solvent concentration [77]. PANI samples were prepared using different acids as dopants, and a four-point probe was applied to determine their electrical properties.

Resistance $(\Omega)$ was employed in accordance with the four-point probe technique. This parameter varies according to the nature, structure and composition of particles and the measurement position. Resistivity $(\Omega \cdot \mathrm{cm})$ is used to represent exact and actual substance characteristics and can be directly computed by multiplying the recorded resistance by a resistivity correction factor (RCF). Given that MCCAT resistivity measurement devices are designed to facilitate RCF computation, the resistivity was evaluated using a straightfor- 
ward method. The sample size was set as $7.5 \times 15(\mathrm{~mm})$ at the fixed position, and RCF was measured as 8.857.

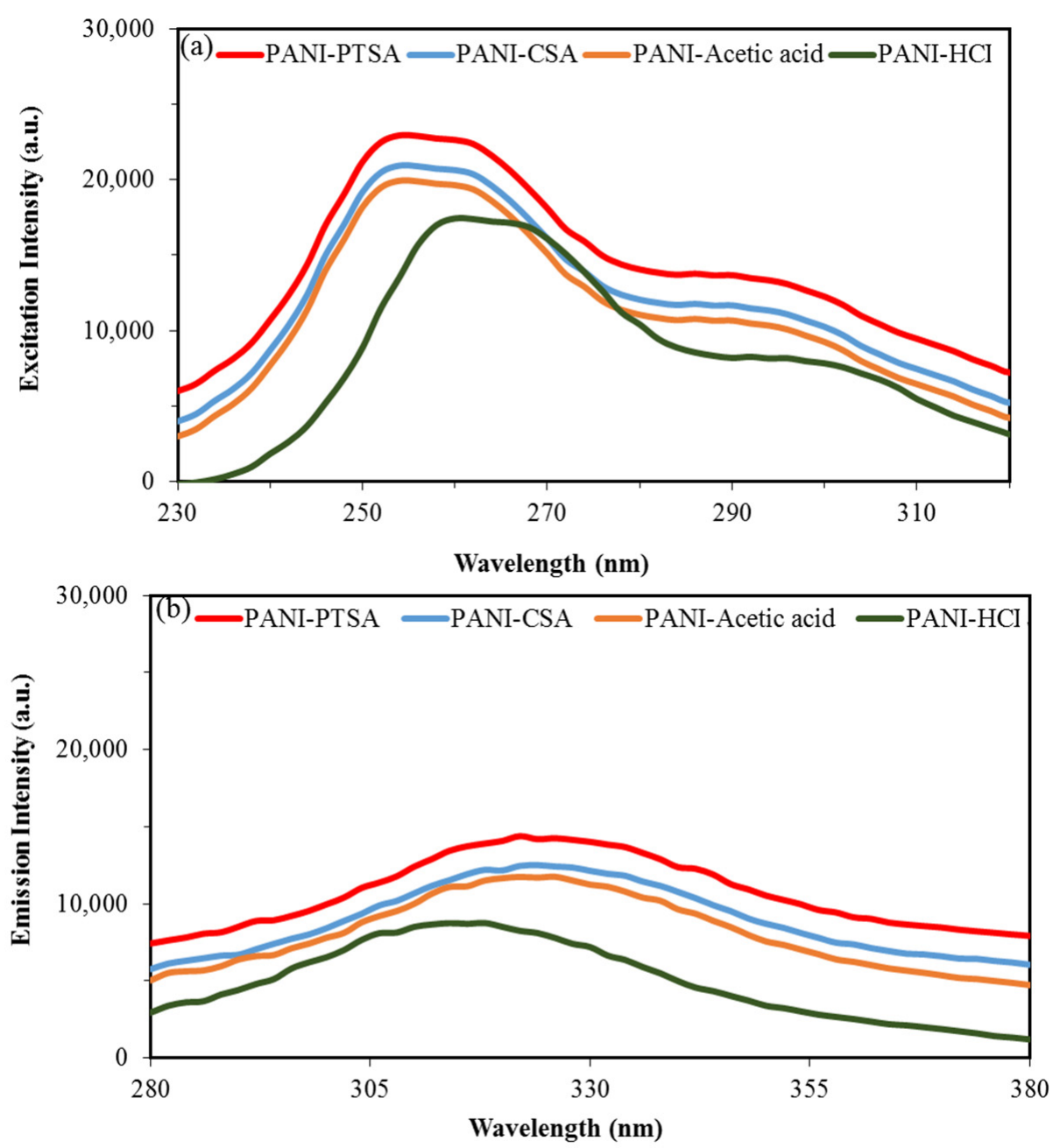

Figure 8. PL spectra of synthesized PANI samples. (a) Excitation photoluminescence peaks. (b) Emission photoluminescence peaks.

In the four-point probe method, the resistance $R(\Omega)$, volume resistivity $\left(R_{v}\right)$ and surface resistivity $(R s)$ of samples were calculated using Equations (7)-(9):

$$
R(\Omega)=\frac{U(\mathrm{~V})}{I(\mathrm{~A})}
$$

According to the Ohm rule, the current (I) flowing through a conductor between two locations is equal to their potential difference $(\mathrm{V})$ and inversely related to their resistance $(R)$.

Volume resistivity $\left(R_{v}\right)$, also known as special resistance, is the resistance per unit volume of the specimen. This phrase is most commonly used in substance sorting $(\Omega \cdot \mathrm{cm})$. For this parameter, every substance is assumed to possess a particular specific percentage.

$$
R_{v}(\Omega . \mathrm{cm})=R(\Omega) \times R C F \times t(\mathrm{~cm})
$$

Surface resistivity $\left(R_{S}\right)$, commonly known as flake resistance, is the resistance per unit of the surface area of a specimen and is presented as $\Omega /$ sq to distinguish it from resistance. 
Given that $R_{s}$ fluctuates with the specimen diameter, most studies assess dye and fine coatings.

$$
R_{S}(\Omega / \mathrm{sq})=R(\Omega) \times R C F=R_{v} \times t^{-1},
$$

where $R$ is resistivity $(\Omega), \mathrm{RCF}$ is resistivity correction factor, and $t[\mathrm{~cm}]$ is thickness. Thus, the effect of RCF on the resistivity of a specimen depends on measurement location, specimen dimensions and diameter.

Conductivity $(\sigma)$, also called specific conductivity, is inversely related to volume resistivity (unit of $S / \mathrm{cm}$ or $(\Omega \cdot \mathrm{cm})^{-1}$ and was computed using Equation (10). The obtained values are listed in Tables 5 and 7.

$$
\sigma(\Omega \cdot \mathrm{cm})^{-1}=\frac{1}{R_{v}}
$$

Table 7. Electrical data of PANI samples.

\begin{tabular}{ccccc}
\hline Sample Name & $\boldsymbol{R}(\boldsymbol{\Omega})$ & $\boldsymbol{R}_{\boldsymbol{s}}(\boldsymbol{\Omega} / \mathbf{s q})$ & $\boldsymbol{R}_{\boldsymbol{v}}(\boldsymbol{\Omega} \cdot \mathbf{c m})$ & Conductivity $_{(\boldsymbol{\Omega} \cdot \mathbf{c m})^{\mathbf{- 1}}}$ \\
\hline PANI-PTSA & $9.98 \times 10^{-1}$ & 8.84 & $2.61 \times 10^{-2}$ & $3.84 \times 10^{1}$ \\
PANI-CSA & $1.31 \times 10^{-1}$ & 1.16 & $3.42 \times 10^{-2}$ & $2.92 \times 10^{1}$ \\
PANI-Acetic acid & $1.53 \times 10^{3}$ & $1.36 \times 10^{4}$ & $4.00 \times 10^{-2}$ & $2.50 \times 10^{-2}$ \\
PANI-HCl & $1.57 \times 10^{3}$ & $1.39 \times 10^{4}$ & $4.10 \times 10^{1}$ & $2.44 \times 10^{-2}$ \\
\hline
\end{tabular}

Table 7 presents the electrical parameters of PANI samples. Their good conductivity values imply the successful production of adequate ES PANI type. The order of conductivity is PANI-PTSA > PANI-HCl > PANI-CSA > PANI-acetic acid. Intensity and charge carrier mobility determine the net conductivity of doped PANI and depend on the dopant nature, the structure of the doped PANI and preparation method $[50,51,58,78]$.

\subsection{Fluorescence Detection of Fluorene}

PL studies confirmed that PANI-PTSA has the best PL intensity among the samples. This finding could be attributed to the orderly arrangement of benzenoid and quinoid units which support the formation of excitons and the enlargement of singlet exciton' delocalization length. With its advanced PL and electrical properties, PANI-PTSA (PANI*) shows an excellent crossing point of providing electrons in sensor application and therefore was selected for fluorene detection. Figure 9 depicts the PL intensity when PANI-PTSA was used detect various fluorene concentrations $(0.001,0.01,0.1,1$ and $10 \mu \mathrm{M})$. As shown in Figure 9a, the specific excitation intensity that activates photoluminescence when PANI* is in contact with fluorene appears at $258 \mathrm{~nm}$. As displayed in Figure 9b, the photoluminescence emission peak related to PANI* in contact with fluorene appears at $324 \mathrm{~nm}$. These results indicate that when fluorene concentration increases from $0.001 \mu \mathrm{M}$ to $10 \mu \mathrm{M}$, the intensity of the photoluminescence peak decreases $[79,80]$.

Stern-Volmer equation was used to study the interaction between PANI and fluorene (Equation (11)) as follows:

$$
\frac{F_{0}}{F}-1=K_{s v} \times C_{D A},
$$

where $F$ and $F_{0}$ are the PL intensity of PANI ${ }^{*}$-fluorene systems and PANI* solution, respectively; $\mathrm{CDA}$ is the quencher (fluorene) concentration, and $K_{s v}$ is the Stern-Volmer quenching constant [81].

A good linear relationship is obtained between PL intensity ratio $\left(\mathrm{F}_{0} / \mathrm{F}-1\right)$ and fluorene concentration in the range of $0.001-10 \mu \mathrm{M}$ (Figure 9c). A photoluminescence test was carried out 10 times to evaluate the stability of the photoluminescence properties of PANI*. The standard error, standard deviation $(\sigma)$ and slope of variation curve are $0.0009,0.002$ and 0.026 , respectively. The limit of detection (LOD) is proportional to the standard deviation $(\sigma)$ and slop $(K)$ of variation of photoluminescence intensity with fluorene concentration. Therefore, the $\operatorname{LOD}(\operatorname{LOD}=(3.3 \times \sigma) / K)$ is approximately 0.26 . Table 8 shows the com- 
parison of detection results for fluorene sensors with different fluorescence spectroscopy methods.
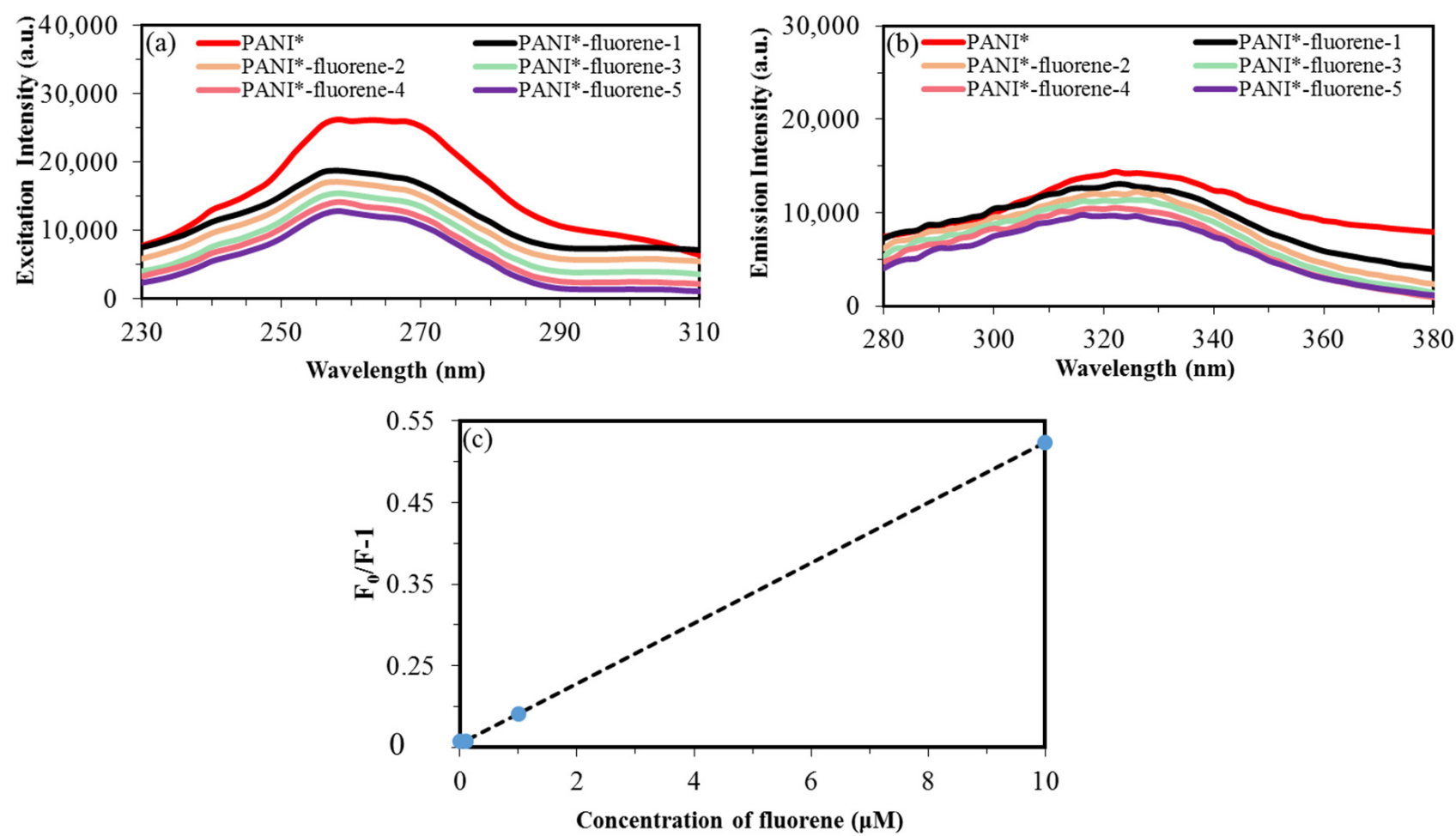

Figure 9. (a) Excitation photoluminescence peaks. (b) Emission photoluminescence peaks of fluorene in concentrations of $0.001,0.01,0.1,1$ and $10 \mu \mathrm{M}$ upon interaction with PANI*. (c) Variation of intensity peaks when PANI* interacted with fluorene.

Table 8. Comparison of fluorene sensors with different detection techniques according to fluorescence obtained during experimental measurements.

\begin{tabular}{clccc}
\hline No. & Fluorescent Sensor Methods & Linear Range $(\mu \mathrm{M})$ & LOD (nM) & References \\
\hline 1 & $\begin{array}{l}\text { Eu(III)-(CCA) } 2 \text { probe } \\
\text { Thin-layer chromatography (TLC) }\end{array}$ & $0.1-1.9$ & 0.43 & {$[82]$} \\
{$\left[\begin{array}{c}1,3-\text {-bis(cyanomethoxy)-tert- } \\
\text { butylcalix[4]arene (CAD) onto CdSe quantum } \\
\text { dots (QDs) CAD@CdSe }\end{array}\right.$} & $0-20$ & 0.8 & {$[84]$} \\
3 & PANI doped PTSA & $0.001-10$ & 0.26 & Current study \\
\hline
\end{tabular}

\section{Conclusions}

PANI-PTSA, PANI-CSA, PANI-acetic acid and PANI-HCl were successfully prepared through chemical oxidative polymerization. The optical, thermal, and electrical properties of PANI rely on the nature and particle quantity of the acid dopant. UV-vis and FT-IR spectra showed that doping creates fundamental varieties inside PANI chains. PANI-PTSA, PANI-CSA and PANI-acetic acid appear as fibrous crystals when compressed. PANI$\mathrm{HCl}$ presents as agglomerated ball crystals because the molecular chain stretches along the direction of mixing and shear forces during polymer crystallization. An XRD study revealed that the chain length grows with the increasing acidity. When the dopant quantity increases, crystallinity decreases, and inter-chain separation and d-spacing increase. As a result, the mobility of load carriers along with a polymer chain and over chains decreases, and conductivity declines. PANI-PTSA exhibits the highest conductivity among the PANI samples. Additionally, TGA results implied that acidity affects the thermal stability of PANI. PL studies confirmed that among the samples, PANI-PTSA has the best PL intensity because 
of the orderly arrangement of benzenoid and quinoid units that support the formation of excitons and the enlargement of singlet exciton' delocalization length. Therefore, PANIPTSA (PANI ${ }^{*}$ ) with advanced PL and $0.26 \mathrm{nM}$ detection limit shows a good balance of providing an electron and detecting fluorene in sensor applications.

Author Contributions: Conceptualization, M.B. and A.R.S.; Formal analysis, M.B.; Investigation, M.B.; Project administration, S.S. and A.R.S.; Supervision, S.A.R. and S.S.; Visualization, M.B.; Writing—original draft, M.B.; Writing—review and editing, S.A.R., S.S. and A.R.S. All authors have read and agreed to the published version of the manuscript.

Funding: This research was funded by the Universiti Putra Malaysia via Geran Universiti Putra Malaysia Inisiatif Putra Berimpak 9674700.

Institutional Review Board Statement: Not applicable.

Informed Consent Statement: Not applicable.

Data Availability Statement: The data presented in this study are available on request from the corresponding author.

Acknowledgments: The authors would like to thank the Universiti Putra Malaysia for its financial support.

Conflicts of Interest: The authors declare no conflict of interest. The funders had no role in the design of the study; in the collection, analyses, or interpretation of data; in the writing of the manuscript, or in the decision to publish the results.

\section{References}

1. Kapp, R. Fluorine. In Encyclopedia of Toxicology; Elsevier: Amsterdam, The Netherlands, 2005; pp. 343-346.

2. Yang, L.; Watts, D.J. Particle surface characteristics may play an important role in phytotoxicity of alumina nanoparticles. Toxicol. Lett. 2005, 158, 122-132. [CrossRef] [PubMed]

3. Alfano, B.; Massera, E.; De Maria, A.; De Girolamo, A.; Di Francia, G.; Delli Veneri, P.; Napolitano, T.; Borriello, A. Polyaniline proton doping for sensor application. In Proceedings of the 2015 XVIII AISEM Annual Conference, Trento, Italy, 3-5 February 2015; IEEE: Piscataway, NJ, USA, 2015; pp. 1-4.

4. Quijada, C. Special Issue: Conductive Polymers: Materials and Applications. Materials 2020, 13, 2344. [CrossRef]

5. Abdolahi, A.; Hamzah, E.; Ibrahim, Z.; Hashim, S. Synthesis of uniform polyaniline nanofibers through interfacial polymerization. Materials 2012, 5, 1487-1494. [CrossRef]

6. Namsheer, K.; Rout, C.S. Conducting polymers: A comprehensive review on recent advances in synthesis, properties and applications. RSC Adv. 2021, 11, 5659-5697. [CrossRef]

7. Chen, S.; Li, B.; Xiao, R.; Luo, H.; Yu, S.; He, J.; Liao, X. Design an Epoxy Coating with $\mathrm{TiO}_{2} / \mathrm{GO} /$ PANI Nanocomposites for Enhancing Corrosion Resistance of Q235 Carbon Steel. Materials 2021, 14, 2629. [CrossRef] [PubMed]

8. Yuan, Y.; Wu, H.; Bu, X.; Wu, Q.; Wang, X.; Han, C.; Li, X.; Wang, X.; Liu, W. Improving Ammonia Detecting Performance of Polyaniline Decorated rGO Composite Membrane with GO Doping. Materials 2021, 14, 2829. [CrossRef] [PubMed]

9. Liu, S.; Liu, L.; Meng, F.; Li, Y.; Wang, F. Protective Performance of Polyaniline-Sulfosalicylic Acid/Epoxy Coating for 5083 Aluminum. Materials 2018, 11, 292. [CrossRef]

10. Beygisangchin, M.; Abdul Rashid, S.; Shafie, S.; Sadrolhosseini, A.R.; Lim, H.N. Preparations, Properties, and Applications of Polyaniline and Polyaniline Thin Films-A Review. Polymers 2021, 13, 2003. [CrossRef]

11. Lin, Y.-C.; Zhong, X.-X.; Huang, H.-X.; Wang, H.-Q.; Feng, Q.-P.; Li, Q.-Y. Preparation and Application of Polyaniline Doped with Different Sulfonic Acids for Supercapacitor. Acta Phys. Chim. Sin. 2016, 32, 474-480. [CrossRef]

12. Li, Z.; Gong, L. Research Progress on Applications of Polyaniline (PANI) for Electrochemical Energy Storage and Conversion. Materials 2020, 13, 548. [CrossRef] [PubMed]

13. Brachetti-Sibaja, S.B.; Palma-Ramírez, D.; Torres-Huerta, A.M.; Domínguez-Crespo, M.A.; Dorantes-Rosales, H.J.; RodríguezSalazar, A.E.; Ramírez-Meneses, E. Cvd conditions for mwcnts production and their effects on the optical and electrical properties of ppy/mwcnts, pani/mwcnts nanocomposites by in situ electropolymerization. Polymers 2021, 13, 351. [CrossRef] [PubMed]

14. Lyu, H. Triple layer tungsten trioxide, graphene, and polyaniline composite films for combined energy storage and electrochromic applications. Polymers 2020, 12, 49. [CrossRef] [PubMed]

15. Silakhori, M.; Naghavi, M.; Metselaar, H.; Mahlia, T.; Fauzi, H.; Mehrali, M. Accelerated Thermal Cycling Test of Microencapsulated Paraffin Wax/Polyaniline Made by Simple Preparation Method for Solar Thermal Energy Storage. Materials 2013, 6, 1608-1620. [CrossRef] [PubMed]

16. Jang, C.; Park, J.-K.; Yun, G.-H.; Choi, H.H.; Lee, H.-J.; Yook, J.-G. Radio-Frequency/Microwave Gas Sensors Using Conducting Polymer. Materials 2020, 13, 2859. [CrossRef] [PubMed] 
17. Ramanavicius, S.; Ramanavicius, A. Conducting polymers in the design of biosensors and biofuel cells. Polymers 2021, 13, 49. [CrossRef]

18. Zarach, Z.; Trzciński, K.; Łapiński, M.; Lisowska-Oleksiak, A.; Szkoda, M. Improving the Performance of a Graphite Foil/Polyaniline Electrode Material by a Thin PEDOT:PSS Layer for Application in Flexible, High Power Supercapacitors. Materials 2020, 13, 5791. [CrossRef]

19. Ghorbani, F.; Zamanian, A.; Aidun, A. Conductive electrospun polyurethane-polyaniline scaffolds coated with poly(vinyl alcohol)-GPTMS under oxygen plasma surface modification. Mater. Today Commun. 2020, 22, 100752. [CrossRef]

20. Llorens, E.; Armelin, E.; del Mar Pérez-Madrigal, M.; del Valle, L.; Alemán, C.; Puiggalí, J. Nanomembranes and Nanofibers from Biodegradable Conducting Polymers. Polymers 2013, 5, 1115-1157. [CrossRef]

21. Ahmed, M.; Shahid, M.; Khan, Z.; Ammar, A.; Saboor, A.; Khalid, A.; Hayat, A.; Saeed, A.; Koohgilani, M. Electrochemical Comparison of SAN/PANI/FLG and ZnO/GO Coated Cast Iron Subject to Corrosive Environments. Materials 2018, 11, 2239. [CrossRef]

22. Mohseni, H.R.; Dehghanipour, M.; Dehghan, N.; Tamaddon, F.; Ahmadi, M.; Sabet, M.; Behjat, A. Enhancement of the photovoltaic performance and the stability of perovskite solar cells via the modification of electron transport layers with reduced graphene oxide/polyaniline composite. Sol. Energy 2021, 213, 59-66. [CrossRef]

23. Zhou, D.D.; Cui, X.T.; Hines, A.; Greenberg, R.J. Conducting polymers in neural stimulation applications. In Implantable Neural Prostheses 2; Springer: Berlin/Heidelberg, Germany, 2009; pp. 217-252.

24. Gospodinova, N.; Terlemezyan, L. Conducting polymers prepared by oxidative polymerization: Polyaniline. Prog. Polym. Sci. 1998, 23, 1443-1484. [CrossRef]

25. Bhadra, S.; Khastgir, D.; Singha, N.K.; Lee, J.H. Progress in preparation, processing and applications of polyaniline. Prog. Polym. Sci. 2009, 34, 783-810. [CrossRef]

26. Yan, H.; Sada, N.; Toshima, N. Thermal transporting properties of electrically conductive polyaniline films as organic thermoelectric materials. J. Therm. Anal. Calorim. 2002, 69, 881-887. [CrossRef]

27. Kulkarni, M.V.; Viswanath, A.K.; Marimuthu, R.; Seth, T. Spectroscopic, transport, and morphological studies of polyaniline doped with inorganic acids. Polym. Eng. Sci. 2004, 44, 1676-1681. [CrossRef]

28. Borole, D.; Kapadi, U.; Kumbhar, P.; Hundiwale, D. Influence of inorganic and organic supporting electrolytes on the electrochemical synthesis of polyaniline, poly(o-toluidine) and their copolymer thin films. Mater. Lett. 2002, 56, 685-691. [CrossRef]

29. Stafström, S.; Brédas, J.L.; Epstein, A.J.; Woo, H.S.; Tanner, D.B.; Huang, W.S.; MacDiarmid, A.G. Polaron lattice in highly conducting polyaniline: Theoretical and optical studies. Phys. Rev. Lett. 1987, 59, 1464-1467. [CrossRef] [PubMed]

30. Sinha, S.; Bhadra, S.; Khastgir, D. Effect of dopant type on the properties of polyaniline. J. Appl. Polym. Sci. 2009, 112, 3135-3140. [CrossRef]

31. Abdiryim, T.; Jamal, R.; Nurulla, I. Doping effect of organic sulphonic acids on the solid-state synthesized polyaniline. J. Appl. Polym. Sci. 2007, 105, 576-584. [CrossRef]

32. Kulkarni, M.V.; Viswanath, A.K.; Marimuthu, R.; Seth, T. Synthesis and characterization of polyaniline doped with organic acids. J. Polym. Sci. Part A Polym. Chem. 2004, 42, 2043-2049. [CrossRef]

33. Hatchett, D.W.; Josowicz, M.; Janata, J. Acid Doping of Polyaniline: Spectroscopic and Electrochemical Studies. J. Phys. Chem. B 1999, 103, 10992-10998. [CrossRef]

34. Bredas, J.L.; Street, G.B. Polarons, bipolarons, and solitons in conducting polymers. Acc. Chem. Res. 1985, 18, 309-315. [CrossRef]

35. Le, T.-H.; Kim, Y.; Yoon, H. Electrical and Electrochemical Properties of Conducting Polymers. Polymers 2017, 9, 150. [CrossRef]

36. Cho, S.; Lee, J.S.; Joo, H. Recent Developments of the Solution-Processable and Highly Conductive Polyaniline Composites for Optical and Electrochemical Applications. Polymers 2019, 11, 1965. [CrossRef]

37. Amiri, A.; Baghayeri, M.; Koshki, M.-S. Electrochemical Deposition of Polyaniline on the Stainless Steel Mesh for the Extraction of Polycyclic Aromatic Hydrocarbons. SSRN Electron. J. 2021, 1, 1-10. [CrossRef]

38. Na, W.; Liu, Q.; Sui, B.; Hu, T.; Su, X. Highly sensitive detection of acid phosphatase by using a graphene quantum dots-based förster resonance energy transfer. Talanta 2016, 161, 469-475. [CrossRef] [PubMed]

39. Usman, F.; Dennis, J.O.; Seong, K.C.; Yousif Ahmed, A.; Meriaudeau, F.; Ayodele, O.B.; Tobi, A.R.; Rabih, A.A.S.; Yar, A. Synthesis and characterisation of a ternary composite of polyaniline, reduced graphene-oxide and chitosan with reduced optical band gap and stable aqueous dispersibility. Results Phys. 2019, 15, 102690. [CrossRef]

40. Saravanan, S.; Joseph Mathai, C.; Anantharaman, M.R.; Venkatachalam, S.; Prabhakaran, P.V. Investigations on the electrical and structural properties of polyaniline doped with camphor sulphonic acid. J. Phys. Chem. Solids 2006, 67, 1496-1501. [CrossRef]

41. Trchová, M.; Stejskal, J. Polyaniline: The infrared spectroscopy of conducting polymer nanotubes (IUPAC Technical Report). Pure Appl. Chem. 2011, 83, 1803-1817. [CrossRef]

42. Chen, S.A.; Lee, H.T. Polyaniline plasticized with 1-methyl-2-pyrrolidone: Structure and doping behavior. Macromolecules 1993, 26, 3254-3261. [CrossRef]

43. Han, D.; Chu, Y.; Yang, L.; Liu, Y.; Lv, Z. Reversed micelle polymerization: A new route for the synthesis of DBSA-polyaniline nanoparticles. Colloids Surf. A Physicochem. Eng. Asp. 2005, 259, 179-187. [CrossRef]

44. Cai, L.-T.; Yao, S.-B.; Zhou, S.-M. Effects of the magnetic field on the polyaniline film studied by in situ conductivity measurements and X-ray diffraction. J. Electroanal. Chem. 1997, 421, 45-48. [CrossRef] 
45. Bala, P.; Samantaray, B.K.; Srivastava, S.K.; Nando, G.B. Organomodified montmorillonite as filler in natural and synthetic rubber. J. Appl. Polym. Sci. 2004, 92, 3583-3592. [CrossRef]

46. Jayakannan, M.; Annu, S.; Ramalekshmi, S. Structural effects of dopants and polymerization methodologies on the solid-state ordering and morphology of polyaniline. J. Polym. Sci. Part B Polym. Phys. 2005, 43, 1321-1331. [CrossRef]

47. Rathore, B.S.; Chauhan, N.P.S.; Rawal, M.K.; Ameta, S.C.; Ameta, R. Chitosan-polyaniline-copper(II) oxide hybrid composite for the removal of methyl orange dye. Polym. Bull. 2020, 77, 4833-4850. [CrossRef]

48. Diggikar, R.S.; Deshmukh, S.P.; Thopate, T.S.; Kshirsagar, S.R. Performance of Polyaniline Nanofibers (PANI NFs) as PANI NFs-Silver (Ag) Nanocomposites (NCs) for Energy Storage and Antibacterial Applications. ACS Omega 2019, 4, 5741-5749. [CrossRef]

49. Ajekwene, K.K.; Kurian, T. Bulk and nano-structured polyaniline: Synthesis, characterization, thermal behaviour and dc conductivity. Int. J. Res. Advent Technol. 2018, 6, 2321-9637.

50. Bhadra, S.; Singha, N.K.; Khastgir, D. Dual functionality of PTSA as electrolyte and dopant in the electrochemical synthesis of polyaniline, and its effect on electrical properties. Polym. Int. 2007, 56, 919-927. [CrossRef]

51. Bhadra, S.; Singha, N.K.; Khastgir, D. Polyaniline by new miniemulsion polymerization and the effect of reducing agent on conductivity. Synth. Met. 2006, 156, 1148-1154. [CrossRef]

52. Geethalakshmi, D.; Muthukumarasamy, N.; Balasundaraprabhu, R. CSA-doped PANI semiconductor nanofilms: Synthesis and characterization. J. Mater. Sci. Mater. Electron. 2015, 26, 7797-7803. [CrossRef]

53. Bednarczyk, K.; Matysiak, W.; Tański, T.; Janeczek, H.; Schab-Balcerzak, E.; Libera, M. Effect of polyaniline content and protonating dopants on electroconductive composites. Sci. Rep. 2021, 11, 7487. [CrossRef]

54. Bai, X.L.; Mei, J.T.; Bai, Y.; Mu, Z.G. Synthesis and Characterization of Polyaniline Nanotubes Doped with Amino Acetic Acid. Appl. Mech. Mater. 2012, 184-185, 1285-1288. [CrossRef]

55. Karaoğlan, N.; Bindal, C. Synthesis and optical characterization of benzene sulfonic acid doped polyaniline. Eng. Sci. Technol. Int. J. 2018, 21, 1152-1158. [CrossRef]

56. Al-Daghman, A.N.J.; Ibrahim, K.; Ahmed, N.M.; Al-Messiere, M.A. Effect of doping by stronger ions salt on the microstructure of conductive polyaniline-ES: Structure and properties. J. Optoelectron. Biomed. Mater. 2016, 8, 175-183.

57. Swaruparani, H.; Basavaraja, S.; Basavaraja, C.; Huh, D.S.; Venkataraman, A. A new approach to soluble polyaniline and its copolymers with toluidines. J. Appl. Polym. Sci. 2010, 117, 1350-1360. [CrossRef]

58. Bhadra, S.; Singha, N.K.; Khastgir, D. Electrochemical synthesis of polyaniline and its comparison with chemically synthesized polyaniline. J. Appl. Polym. Sci. 2007, 104, 1900-1904. [CrossRef]

59. Li, X.-G.; Li, A.; Huang, M.-R. Facile High-Yield Synthesis of Polyaniline Nanosticks with Intrinsic Stability and Electrical Conductivity. Chem. Eur. J. 2008, 14, 10309-10317. [CrossRef]

60. Neelgund, G.M.; Oki, A. A facile method for the synthesis of polyaniline nanospheres and the effect of doping on their electrical conductivity. Polym. Int. 2011, 60, 1291-1295. [CrossRef] [PubMed]

61. Huang, J.; Virji, S.; Weiller, B.H.; Kaner, R.B. Polyaniline Nanofibers: Facile Synthesis and Chemical Sensors. J. Am. Chem. Soc. 2003, 125, 314-315. [CrossRef]

62. Casado, U.M.; Quintanilla, R.M.; Aranguren, M.I.; Marcovich, N.E. Composite films based on shape memory polyurethanes and nanostructured polyaniline or cellulose-polyaniline particles. Synth. Met. 2012, 162, 1654-1664. [CrossRef]

63. Huang, J.; Kaner, R.B. The intrinsic nanofibrillar morphology of polyaniline. Chem. Commun. 2006, 4, 367-376. [CrossRef]

64. Banerjee, S.; Kumar, A. Dielectric behavior and charge transport in polyaniline nanofiber reinforced PMMA composites. J. Phys. Chem. Solids 2010, 71, 381-388. [CrossRef]

65. Rahayu, I.; Eddy, D.R.; Novianty, A.R.; Anggreni, A.; Bahti, H.; Hidayat, S. The effect of hydrochloric acid-doped polyaniline to enhance the conductivity. IOP Conf. Ser. Mater. Sci. Eng. 2019, 509, 012051. [CrossRef]

66. Jing, X.; Wang, Y.; Wu, D.; Qiang, J. Sonochemical synthesis of polyaniline nanofibers. Ultrason. Sonochem. 2007, 14, 75-80. [CrossRef]

67. Saini, P.; Arora, M.; Arya, S.K.; Tawale, J.S. Effect of controlled doping on electrical properties and permittivity of PTSA doped polyanilines and their EMI shielding performance. Indian J. Pure Appl. Phys. 2014, 52, 175-182.

68. Yang, L.; Zhang, C. Sen Effect of Dopants on Microstructure and Properties of Polyaniline and Polypyrrole. Adv. Mater. Res. 2011, 328-330, 1576-1579. [CrossRef]

69. Kumar, N.A.; Choi, H.J.; Shin, Y.R.; Chang, D.W.; Dai, L.; Baek, J.B. Polyaniline-grafted reduced graphene oxide for efficient electrochemical supercapacitors. ACS Nano 2012, 6, 1715-1723. [CrossRef] [PubMed]

70. Meriga, V.; Valligatla, S.; Sundaresan, S.; Cahill, C.; Dhanak, V.R.; Chakraborty, A.K. Optical, electrical, and electrochemical properties of graphene based water soluble polyaniline composites. J. Appl. Polym. Sci. 2015, 132. [CrossRef]

71. Arora, M.; Arya, S.K.; Barala, S.K.; Saini, P. Magnetic resonance and electrical properties of p-toluene sulphonic acid doped polyaniline. Appl. Phys. Mater. Sci. AIP Conf. Proc. 2013, 1536, 1235-1236. [CrossRef]

72. Yan, F.; Xue, G. Synthesis and characterization of electrically conducting polyaniline in water-oil microemulsion. J. Mater. Chem. 1999, 9, 3035-3039. [CrossRef]

73. Babu, V.J.; Vempati, S.; Ramakrishna, S. Conducting Polyaniline-Electrical Charge Transportation. Mater. Sci. Appl. 2013, 4, 1-10. [CrossRef] 
74. Shimano, J.Y.; MacDiarmid, A.G. Polyaniline, a dynamic block copolymer: Key to attaining its intrinsic conductivity? Synth. Met. 2001, 123, 251-262. [CrossRef]

75. Wohlgenannt, M.; Vardeny, Z. V Spin-dependent exciton formation rates in -conjugated materials. J. Phys. Condens. Matter 2003, 15, R83-R107. [CrossRef]

76. Chiang, J.C.; MacDiarmid, A.G. "Polyaniline": Protonic acid doping of the emeraldine form to the metallic regime. Synth. Met. 1986, 13, 193-205. [CrossRef]

77. Cao, Y.; Andreatta, A.; Heeger, A.J.; Smith, P. Influence of chemical polymerization conditions on the properties of polyaniline. Polymer 1989, 30, 2305-2311. [CrossRef]

78. Bhadra, S.; Singha, N.K.; Chattopadhyay, S.; Khastgir, D. Effect of different reaction parameters on the conductivity and dielectric properties of polyaniline synthesized electrochemically and modeling of conductivity against reaction parameters through regression analysis. J. Polym. Sci. Part B Polym. Phys. 2007, 45, 2046-2059. [CrossRef]

79. Sui, B.; Kim, B.; Zhang, Y.; Frazer, A.; Belfield, K.D. Highly Selective Fluorescence Turn-On Sensor for Fluoride Detection. ACS Appl. Mater. Interfaces 2013, 5, 2920-2923. [CrossRef]

80. Sadrolhosseini, A.R.; Krishnan, G.; Safie, S.; Beygisangchin, M.; Rashid, S.A.; Harun, S.W. Enhancement of the fluorescence property of carbon quantum dots based on laser ablated gold nanoparticles to evaluate pyrene. Opt. Mater. Express 2020, 10, 2227-2241. [CrossRef]

81. Li, Y.; Chen, J.; Wang, Y.; Li, H.; Yin, J.; Li, M.; Wang, L.; Sun, H.; Chen, L. Large-scale direct pyrolysis synthesis of excitationindependent carbon dots and analysis of ferric (III) ion sensing mechanism. Appl. Surf. Sci. 2021, 538, 148151. [CrossRef]

82. Abbas, A.M.; Anwar, Z.M.; Soliman, Y.A.; Abdel-Hadi, M.M.; Kamel, R.M. A turn-off luminescent europium probe for efficient and sensitive detection of some low molecular weight polycyclic aromatic hydrocarbons in seawater. Microchem. J. 2020, 159, 105471. [CrossRef]

83. Rau, A. Basic experiments in thin-layer chromatography-fourier transform Raman spectrometry. J. Raman Spectrosc. 1993, 24, 251-254. [CrossRef]

84. Kumar, R.; Arora, M.; Jain, A.K.; Babu, J.N. 1,3-Bis(cyanomethoxy)calix[4]arene capped CdSe quantum dots for the fluorogenic sensing of fluorene. RSC Adv. 2017, 7, 14015-14020. [CrossRef] 